\title{
Deep structure of Japan subduction zone as derived from local, regional, and teleseismic events
}

\author{
Dapeng Zhao \\ Seismological Laboratory, California Institute of Technology, Pasadena
}

\author{
Akira Hasegawa \\ Tohoku University, Sendai, Japan

\section{Hiroo Kanamori} \\ Seismological Laboratory, California Institute of Technology, Pasadena
}

Observation Center for Prediction of Earthquakes and Volcanic Eruptions, Faculty of Science,

\begin{abstract}
We have determined a detailed three-dimensional $P$ wave velocity structure of the Japan subduction zone to $500-\mathrm{km}$ depth by inverting local, regional, and teleseismic data simultaneously. We used 45,318 $P$ wave arrivals from 1241 shallow and deep earthquakes which occurred in and around the Japan Islands. The arrival times are recorded by the Japan University Seismic Network which covers the entire Japan Islands densely and uniformly. We also used 4211 travel time residuals from 100 teleseismic events which are read from seismograms recorded by seismic stations in northeastern Japan. In comparison with the previous results obtained from only local and regional events, the present result for the area around the lower plate boundary and the mantle below the plate is determined more reliably because of the addition of 7035 data from 100 teleseismic events and 41 very deep earthquakes. In the crust and uppermost mantle, low-velocity zones are clearly visible beneath active volcanoes. In the mantle wedge the low-velocity zones generally parallel with the slab and exist continuously to a depth of about $200-\mathrm{km}$, which is consistent with the petrological, geochemical and geodynamic studies. We consider that the existence of volcanism-related low-velocity anomalies in the mantle wedge is a general seismological characteristic of subduction zones, in light of all the available tomographic results for many subduction zones in the world. The Pacific slab beneath Japan is imaged more clearly than in previous studies as a high-velocity zone with a thickness of $80-90 \mathrm{~km}$ and a $P$ wave velocity $4-6 \%$ higher than the normal mantle. Lower velocity anomalies are found in the mantle below the slab.
\end{abstract}

\section{Introduction}

Since the pioneering work by Wadati [1935], who first demonstrated the existence of deep earthquakes beneath the Japan Islands, continuing efforts have been made to study the deep structure of this typical subduction zone. The lateral variation of seismic velocity and attenuation structures beneath Japan was noted earlier by many investigators [e.g., Katsumata, 1960; Hisamoto, 1965a, b; Utsu, 1967; Kanamori, 1968]. Since the advent of plate tectonics, the anomalous structure has been associated with the subducting Pacific plate [Utsu, 1971], which has higher velocity and lower attenuation than the surrounding mantle. Later, many researchers detected and analyzed converted and/or re-

Copyright 1994 by the American Geophysical Union.

Paper number 94JB01149.

0148-0227/94/94JB-01149\$05.00 flected waves at the upper boundary of the subducting Pacific plate and demonstrated that the plate boundary is a very sharp seismic velocity discontinuity [Okada, 1971, 1979; Hasegawa et al., 1978; Matsuzawa et al., 1986, 1990; Obara and Sato, 1988; Obara, 1989]. The plate boundary estimated from the later arrivals is located just above the Wadati-Benioff seismic zone determined from reliable hypocentral locations.

Many researchers have used seismic tomography methods to investigate the three-dimensional (3-D) velocity and attenuation structures beneath Japan, on both regional and local scales. For detailed reviews, see Zhao [1991], Zhao and Hasegawa [1993], and Hasegawa et al. [this issue]. These previous studies confirmed the existence of high-velocity and low-attenuation zones corresponding to the subducted Pacific and Philippine Sea plates, and revealed low-velocity and high-attenuation zones in the crust and mantle wedge beneath active volcanoes. 
Recently, Zhao et al. [1992a] and Zhao and Hasegawa [1993] used an improved tomographic method to study the deep structure of the Japan subduction zone. They have taken into account the effect of the complex shapes of seismic velocity discontinuities such as the Moho and Conrad discontinuities and the upper boundary of the subducting Pacific plate. They used a great number of both first and later arrivals from shallow and deep earthquakes, and adopted an efficient 3-D ray tracing technique to calculate travel times and ray paths. As a result, they determined a detailed 3-D velocity structure of the Japan subduction zone with a much higher resolution than the previous studies.

Zhao et al. [1992a] and Zhao and Hasegawa [1993] used local and regional shallow and deep earthquakes, and determined well the structure of the crust, mantle wedge and around the upper boundary of the subducting Pacific plate. However, their result for the area around the lower boundary of the slab and the mantle below the slab is less reliable because that area is sampled by only the downward diving rays from deep earthquakes which occurred within the slab, and the rays do not crisscross well there.

In this study, we have extended the tomographic method of Zhao et al. [1992a] to make it applicable to simultaneous tomographic inversions of local, regional, and teleseismic event data. Applying this updated method to a large number of high-quality data recorded by the Japan University Seismic Network, we have improved the tomographic image of the Japan subduction zone. The present result provides a clearer picture of the subducting Pacific plate, especially for the area around the lower plate boundary, and the mantle below the plate, thanks to the addition of data from teleseismic events and more deep earthquakes. The new information obtained in this work may help to improve our understanding of the dynamic process of subduction zones.

\section{Data}

In this study, we combined two sets of data to conduct tomographic inversions. One consists of arrival times from shallow and deep earthquakes which occurred in and around the Japan Islands, and the other, travel time residuals from teleseismic events.

\section{Local and regional data}

We used local and regional earthquake arrival times selected from the Japan University Network Earthquake Catalog (JUNEC) (July 1985 - December 1989). The data set is compiled by the Earthquake Research Institute, University of Tokyo, from $P$ and $S$ wave arrival times from earthquakes which occurred in and around Japan and were observed by the separate seismic networks of eight national universities in Japan [Tsuboi et al., 1989]. Figure 1 shows the geographic locations of the 216 stations we used. This united seismic network densely and uniformly covers the entire Japan Islands

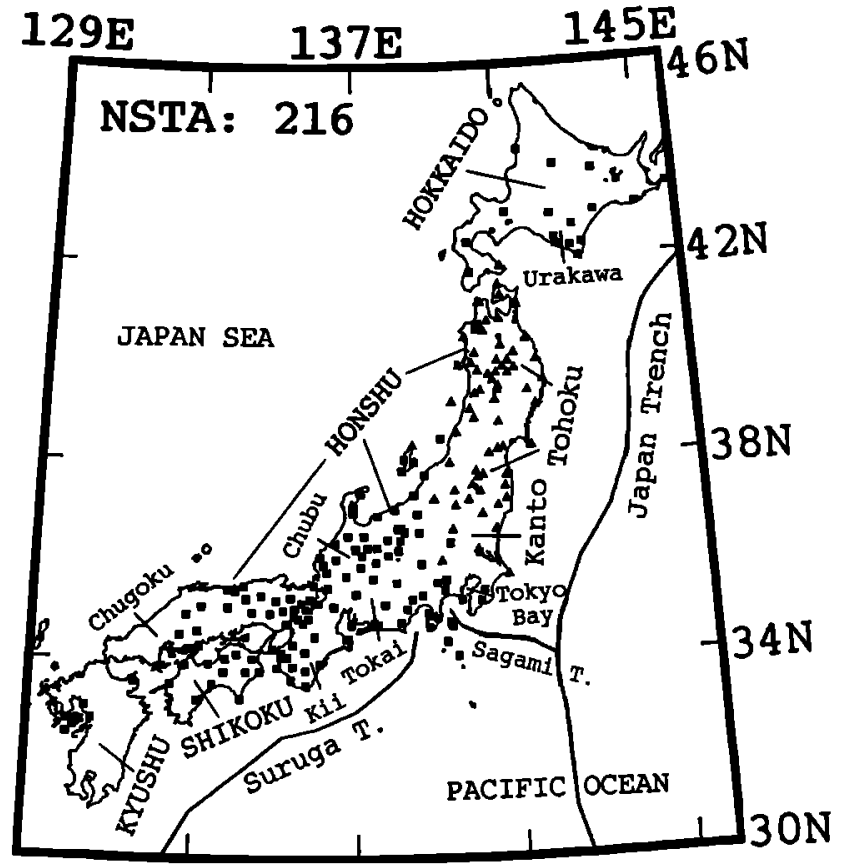

Figure 1. Locations of 216 seismic stations used in this study. Teleseismic data are recorded by the stations in northeastern Japan (solid triangles). Local and regional earthquake data are recorded by all the stations. Main districts in the study area are labeled.

except for Hokkaido and Kyushu, where there are fewer stations. This new data set is superior, in both station density and arrival time accuracy because of the higher sensitivity of seismographs, to the Japan Meteorological Agency data set which has been routinely reported to the International Seismological Center and has been used so far in the tomographic studies in Japan.

Zhao and Hasegawa [1993] used 50,919 arrival times from 512 shallow earthquakes and 688 intermediatedepth and deep earthquakes. The data recorded by the seismic stations of Tohoku University, which are situated in northeastern Japan (triangles in Figure 1), are all re-picked directly from the original seismograms. The data from other stations are collected from JUNEC (July 1985 - December 1986). The data set consists of many arrivals of $S P$ converted waves at the Moho discontinuity, and $P S$ and $S P$ converted waves at the upper boundary of the Pacific plate, which were picked from seismograms recorded by the seismic network of Tohoku University (for details of the later arrivals, see Zhao et al. [1992a]). In this study, we added $2824 P$ wave arrival times from 41 very deep earthquakes to the data set of Zhao and Hasegawa [1993]. The new data were collected from the recent JUNEC issues from January 1987 to December 1989. All of the 41 events have focal depths from 300 - to $600-\mathrm{km}$.

Figures $2 \mathrm{a}$ and $2 \mathrm{~b}$ show epicentral distributions of the 512 shallow events $(0-40 \mathrm{~km})$ and 729 (688 plus 41$)$ intermediate-depth and deep events (40-650 km), respectively. We can see from Figure 2 a that the shallow earthquakes are, on the whole, uniformly distributed in the Japan Islands. Most of the deep earthquakes 
(a)

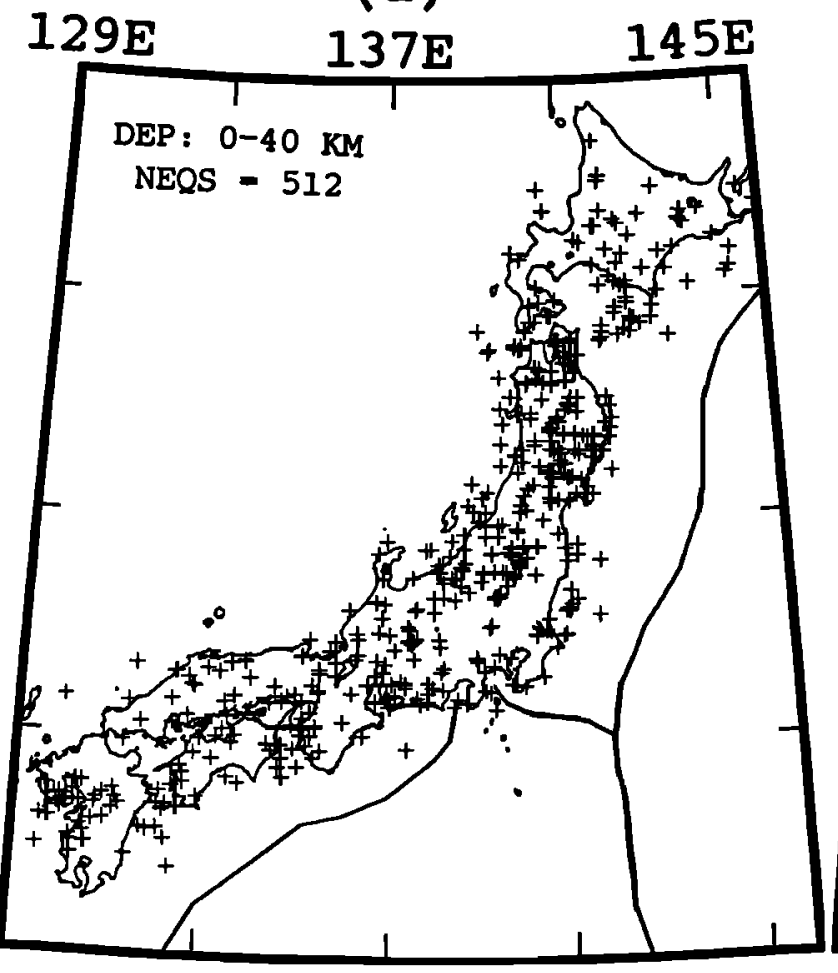

(b)

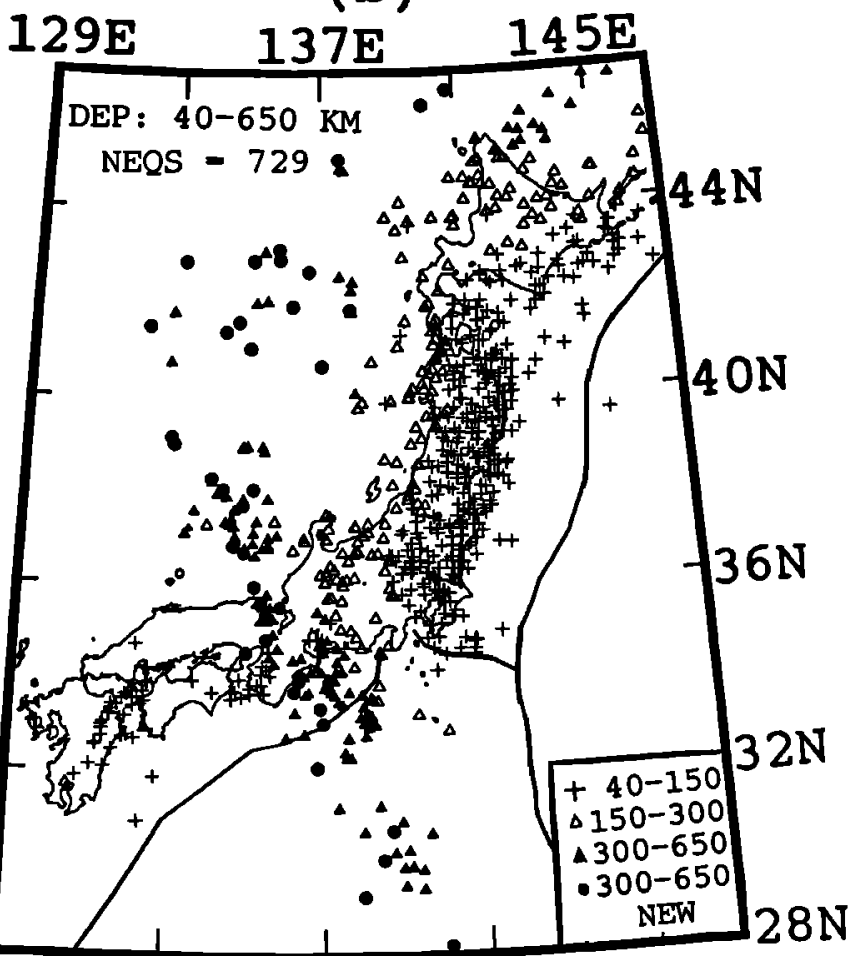

Figure 2. (a) Epicentral locations of 512 earthquakes with focal depths shallower than $40-\mathrm{km}$. (b) Epicentral locations of 729 earthquakes with focal depths from 40- to 650-km. Epicenters are shown in different symbols according to the focal depth. Cross, 40-150 km; open triangle, $150-300 \mathrm{~km}$; solid triangle and solid circle, $300-650 \mathrm{~km}$. Solid triangles denote deep events used by Zhao and Hasegawa [1993]; solid circles denote 41 deep earthquakes which are newly added in this study.

are associated with the subduction of the Pacific plate, many of them deeper than 400-km (Figure 2b). Earthquakes deeper than 30-km beneath southwestern Japan are associated with the subduction of the Philippine Sea plate. The 41 deep earthquakes newly collected are shown by dots in Figure $2 \mathrm{~b}$. Note that there are only a total of 128 deep events $(>300-\mathrm{km}$ ) in the original data set of Zhao and Hasegawa [1993] (solid triangles in Figure $2 \mathrm{~b}$ ) because only a few JUNEC issues were available when they collected the data. The addition of the 41 new deep earthquakes in this work significantly improves the coverage of deep events beneath the Japan Sea, which played an important role in the improvement of resolution of the tomographic image, as described below.

The numbers of $P, S$ and later arrivals for the total 1241 earthquakes are $45,318,8141$ and 284 , respectively. The accuracy for most $P$ arrival times is considered to be approximately $0.1 \mathrm{~s}$. The accuracy for some $S$ arrivals, later arrivals and $P$ arrivals with large epicentral distances (e.g., $>300-\mathrm{km}$ ) is relatively low, being 0.2 $0.3 \mathrm{~s}$. Figure 3 shows the number of $P$ wave arrival times versus epicentral distances. Most of the data have epicentral distances from $50-$ to $300-\mathrm{km}$. There are many data with ray paths longer than $900-\mathrm{km}$. The arrival times are corrected for the ellipticity of the Earth.

\section{Teleseismic data}

We read first $P$ wave arrivals for 100 teleseismic events of magnitude $M>5.8$, from short-period verti- cal component seismograms at 67 seismic stations of the seismic network of Tohoku University, which are situated in northeastern Japan (solid triangles in Figure 1). The data set includes those at two stations of Hokkaido University, three stations of Hirosaki University, and three stations of University of Tokyo. The teleseismic events selected occurred between November 1988 and October 1990. Figure 4 shows the geographic locations of the events. We can see that the events selected have a fairly complete azimuthal range except for gaps at $50^{\circ}-90^{\circ}$ and $90^{\circ}-145^{\circ}$ from north. All events were at epicentral distances between $30^{\circ}$ and $90^{\circ}$ from northeastern Japan; thus the effects of complex structures of the core-mantle boundary and the upper mantle are avoided. We only read those $P$ wave arrivals which have a distinct first motion. Waveform characteristics were visually correlated between stations to minimize reading errors and the effects of attenuation. In total, 4211 $P$ wave arrival times were collected from the 100 teleseismic events. The number of arrivals for each event ranges from 25 to 65 . The accuracy of the arrival times is estimated to be $0.1 \mathrm{~s}$ for most of the teleseismic data.

\section{Method}

In this study we modified the original tomographic method of Zhao et al. [1992a] to combine teleseismic residuals with local and regional earthquake arrival times in tomographic inversions. This method can deal with a general velocity model in which complex velocity 


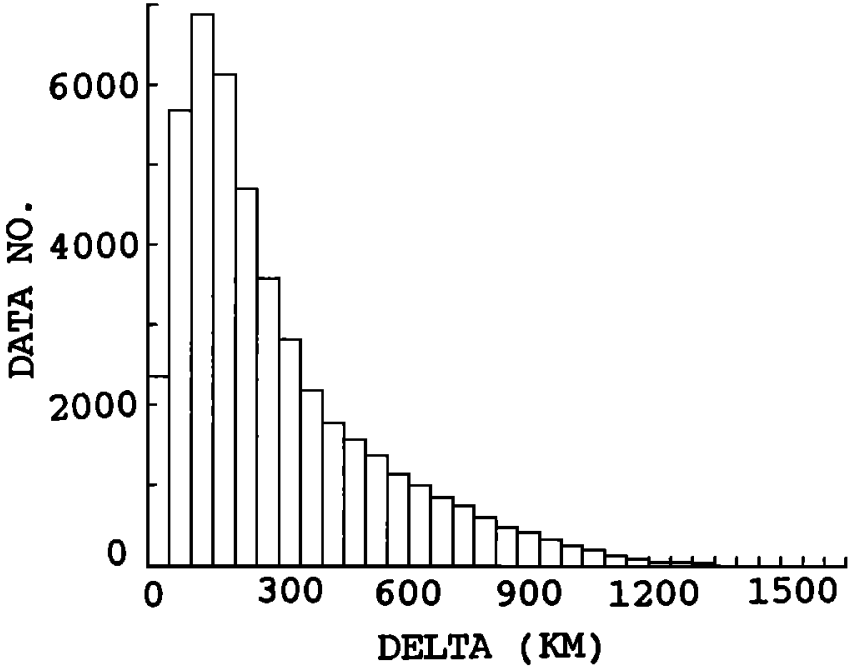

Figure 3. Number of $P$ wave arrival times from local and regional events versus epicentral distances.

discontinuities exist and the velocity changes in threedimensions. The medium under study is divided into layers by the discontinuities. Three-dimensional grid nodes are arranged in every layer. Velocities at grid nodes are taken to be unknown parameters. The velocity at any point in the model is calculated by linearly interpolating the velocities at the eight grid nodes surrounding that point. Local and regional earthquakes are relocated in the inversion process. Arrival times of later phases can be used easily in addition to first ar-

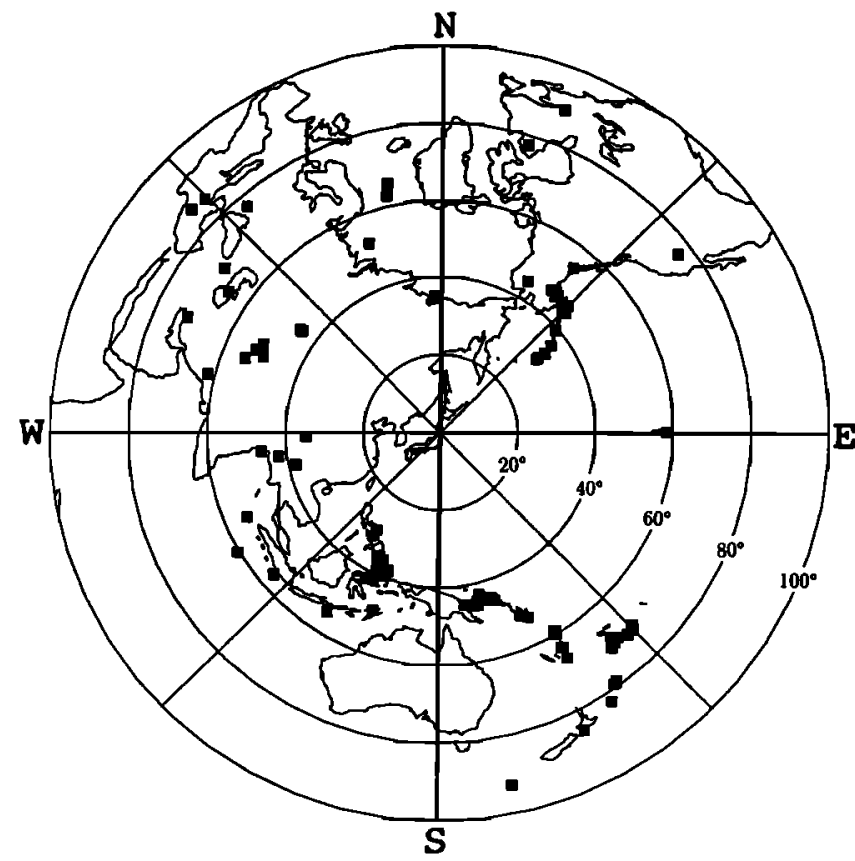

Figure 4. Epicentral locations of the 100 teleseismic events used in this study. Equidistant-azimuthal projection is used. The map center is the center of the seismic network of Tohoku University $\left(38.5^{\circ}, 140.5^{\circ}\right)$. The concentric circles correspond to epicentral distances of $20^{\circ}$, $40^{\circ}, 60^{\circ}, 80^{\circ}$ and $100^{\circ}$. rivals. The nonlinear tomographic problem is solved by iteratively conducting linear inversions until a convergent solution is found.

For local and regional earthquakes which are located in the modeling space, an observed travel time $T_{i j}^{\text {obs }}$ from the $j$ th event at the $i$ th station can be written as

$$
\begin{aligned}
T_{i j}^{\text {obs }}= & T_{i j}^{\mathrm{cal}}+\left(\frac{\partial T}{\partial \varphi}\right)_{i j} \Delta \varphi_{j}+\left(\frac{\partial T}{\partial \lambda}\right)_{i j} \Delta \lambda_{j}+\left(\frac{\partial T}{\partial h}\right)_{i j} \\
& \cdot \Delta h_{j}+\Delta T_{o j}+\sum_{k} \frac{\partial T}{\partial V_{k}} \Delta V_{k}+E_{i j}
\end{aligned}
$$

where $T_{i j}^{\text {cal }}$ is calculated travel time; $\varphi_{j}, \lambda_{j}, h_{j}, T_{o j}$ are latitude, longitude, focal depth, and origin time of the $j$ th event; $V_{k}$ is velocity at the $k$ th grid node; $\Delta$ denotes perturbation of a parameter; and $E_{i j}$ are higher order terms of perturbations and error in the observation. We write the travel time residual as

$$
t_{i j}=T_{i j}{ }^{\text {obs }}-T_{i j}{ }^{\mathrm{cal}} \text {. }
$$

Ray paths of seismic waves for the local and regional earthquakes are entirely located in the modeling space. We used the efficient 3-D ray tracing technique of Zhao et al. [1992a] to trace rays between hypocenters and receivers and calculate theoretical travel times $T_{i j}^{\text {cal }}$ and travel time residuals $t_{i j}$.

For the teleseismic events, we use relative travel time residuals in order to minimize errors introduced by hypocentral mislocations and origin times, and the path effect outside the modeling space. Hypocenters were obtained from the Bulletin of the International Seismological Centre. Raw travel time residuals can also be written as equation (2), but we calculate the theoretical travel times $T_{i j}^{\text {cal }}$ in a different way. We first used the iasp91 1-D Earth model [Kennett and Engdahl, 1991] to determine a teleseismic ray between the hypocenter and receiver and find the intersection between the ray and the bottom plane of the modeling space. Then we trace the ray path between the intersection and receiver by using the 3-D ray tracer of Zhao et al. [1992a]. A relative travel time residual $r_{i j}$ is then calculated from individual station residuals by removing the mean residual $\bar{t}_{j}$ averaged over all stations for each event:

$$
r_{i j}=t_{i j}-\bar{t}_{j} \text {. }
$$

The mean residual is given by

$$
\bar{t}_{j}=\frac{1}{m_{j}} \sum_{i=1}^{m_{j}} t_{i j}
$$

where $m_{j}$ is the number of observed arrivals for the $j$ th event.

These two kinds of residuals form a whole set of data with a column vector $\mathrm{d}$ of dimension $N$. The entire source and medium parameters with a column vector $\mathbf{m}$ can be arranged as

$$
\begin{aligned}
\mathbf{m}^{T}= & \left(\Delta \varphi_{1}, \Delta \lambda_{1}, \Delta h_{1}, \Delta T_{o 1}, \ldots, \Delta \varphi_{M}, \Delta \lambda_{M},\right. \\
& \left.\Delta h_{M}, \Delta T_{o M}, \Delta V_{1}, \ldots, \Delta V_{K}\right)
\end{aligned}
$$


where $K$ is the number of medium parameters, and $M$ the number of local and regional events.

The column vectors specifying the data set and the source and medium parameters can be related as the observation equation

$$
\mathbf{d}=\mathbf{G m}+\mathbf{e}
$$

where $\mathrm{e}$ is an error vector, and $\mathrm{G}$ is an $N \times(4 M+K)$ matrix, whose elements consist of the coefficients of the derivatives in equation (1).

There are several ways to solve equation (6). In the early tomographic studies, $A k i$ and Lee [1976] and $A k i$ et al. [1977] adopted a damped least squares method. They use

$$
\left(\mathbf{G}^{\mathbf{T}} \mathbf{G}+\boldsymbol{\Theta}\right) \mathbf{m}=\mathbf{G}^{\mathbf{T}} \mathbf{d}
$$

which can be obtained by minimizing $|\mathbf{d}-\mathbf{G m}|^{2}+$ $\mathbf{m}^{\mathbf{T}} \boldsymbol{\Theta m}$, where $\Theta$ is the damping factor matrix. The advantage of this method is that the resolution and covariance matrices can be obtained together with the solution vector. The drawback is that the matrix $\mathbf{G}^{\mathbf{T}} \mathbf{G}$ needs a large memory storage and its inversion is time consuming, though $\mathbf{G}$ is a relatively sparse matrix. Thus this approach can only deal with a relatively small tomographic problem with numbers of data and unknowns less than a few thousand. Note that it is not uncommon that hundreds of thousands to millions of data are used to solve tens to hundreds of thousands of unknown parameters in modern tomographic problems.

The damped least squares approach has been improved with the introduction of the parameter separation technique [Pavlis and Booker, 1980; Spencer and Gubbins, 1980]. This technique exploits the ability to construct an orthogonal transformation for each event that annuls the hypocenter components while transforming but still preserving the velocity part of the problem. However, the parameter separation itself is a nontrivial operation and becomes formidable when a great number (e.g., thousands) of earthquakes are used.

Recently, iteration type inversion techniques have been used to solve directly the observation equation (6), to avoid the requirement for the large storage space and the formidable computation of $\mathbf{G}^{\mathbf{T}} \mathbf{G}$. These techniques are, e.g., the algebraic reconstruction technique (ART) [Herman, 1980], the simultaneous iterative reconstruction technique (SIRT) [Humphreys and Clayton, 1988], and the conjugate gradient (CG) method. In this study, we have used a CG type solver, the LSQR algorithm of Paige and Saunders [1982], to solve directly the large and sparse observation equation (6). The LSQR algorithm has been used by several researchers [e.g., $\mathrm{No}$ let, 1985; Spakman and Nolet, 1988; Lees and Crosson, 1989; Zhao et al., 1992a] and is confirmed to be a very efficient algorithm to solve large tomographic problems.

\section{Analyses}

\section{Teleseismic Residuals}

Before conducting tomographic inversions, we first display the observed teleseismic data in two ways to gain an insight into the usefulness and importance of the data. First, the relative residuals for each station are averaged over all 100 events, resulting in a mean relative travel time residual

$$
\bar{r}_{i}=\frac{1}{n_{i}} \sum_{j=1}^{n_{i}} r_{i j}
$$

where $n_{i}$ is the number of events observed at the $i$ th station. These are plotted in Figure 5e. Second, we separate the events into source quadrants according to the azimuth of the source from the network, also referred to as the source azimuth or source direction. We calculate the mean relative residuals for four quadrants: $\mathrm{NE}=\left(0^{\circ}, 90^{\circ}\right), \mathrm{SE}=\left(90^{\circ}, 180^{\circ}\right), \mathrm{SW}=\left(180^{\circ}, 270^{\circ}\right)$, $\mathrm{NW}=\left(270^{\circ}, 360^{\circ}\right)$. The mean residuals for each source quadrant are plotted in Figures 5a-5d.

The mean relative residuals, referred to simply as residuals, averaged for all 100 events (Figure 5e), produce a spatial pattern of early arrivals at stations near the Pacific coast, especially in southeastern Tohoku, and late arrivals at stations along the volcanic front and the Japan Sea coast. This pattern is generally consistent with the main structural feature of the Tohoku region as derived from local earthquake studies [e.g., Zhao

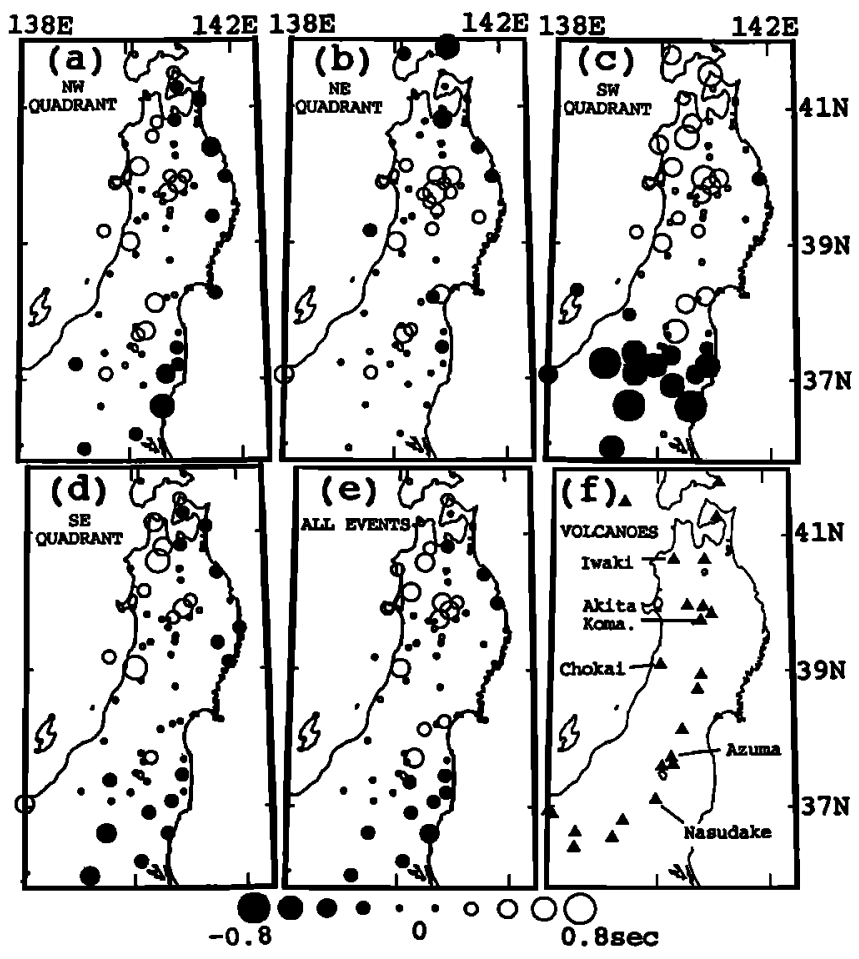

Figure 5. (a)-(d) Relative travel time residuals per source quadrant, calculated with respect to the network average. Quadrants are as follows: (a) northwest, (b) northeast, (c) southwest, (d) southeast. (e) Relative travel time residuals for all 100 teleseismic events. (f) Locations of active volcanoes (solid triangles) in northeastern Japan. Five volcanoes which are mentioned in the text are labeled. The scale for the size of the residuals in Figures 5a-5e is shown at bottom. Solid and open circles denote early and delayed arrivals, respectively. 
et al., 1990a, b, 1992a, b]. Large delayed arrivals exist for stations in volcanic areas, e.g., Akita-Komagatake, Iwaki-San, Chokai-San, and Azuma-San (see Figure 5f for locations of the volcanoes). Although stations in the Nasudake volcanic area show early arrivals, they are much later than those of the adjacent stations.

The pattern and magnitude of the residuals for the events from the NW, NE and SE quadrants are all similar (see Figures 5a, 5b, 5d). The arrivals at stations along the volcanic front and the Japan Sea coast are later than those on the Pacific coast. This is because the rays to stations in central and western Tohoku travel longer in the slow mantle wedge. The early arrivals in northern Tohoku and southern Hokkaido for the events in the NE quadrant are probably caused by the rays traveling in the Pacific plate subducting beneath the Kuriles. The pattern and magnitude of the residuals for events in the SW quadrant (Figure 5c) are very different from those for the other quadrants. The stations in southern Tohoku and northern Kanto show very early arrivals, which are considered to be caused by the change of the geometry of the Pacific plate beneath Kanto. We can see from Figure 6 that the Pacific plate south of Kanto dips toward the southwest and has a larger dip angle $\left(\sim 40^{\circ}-45^{\circ}\right)$ than that north of Kanto $\left(\sim 30^{\circ}\right)$. The incident angle of the teleseismic rays is generally small (within $\sim 30^{\circ}$ of the vertical direction). Thus, for events in the southwestern quadrant, because of the coincidence of the ray direction and the dip direction of the steeper part of the Pacific plate, the rays arriving at stations in northern Kanto and southern Tohoku travel longer in the high-velocity Pacific plate than the rays at the northern areas, resulting in earlier arrivals in northern Kanto and southern

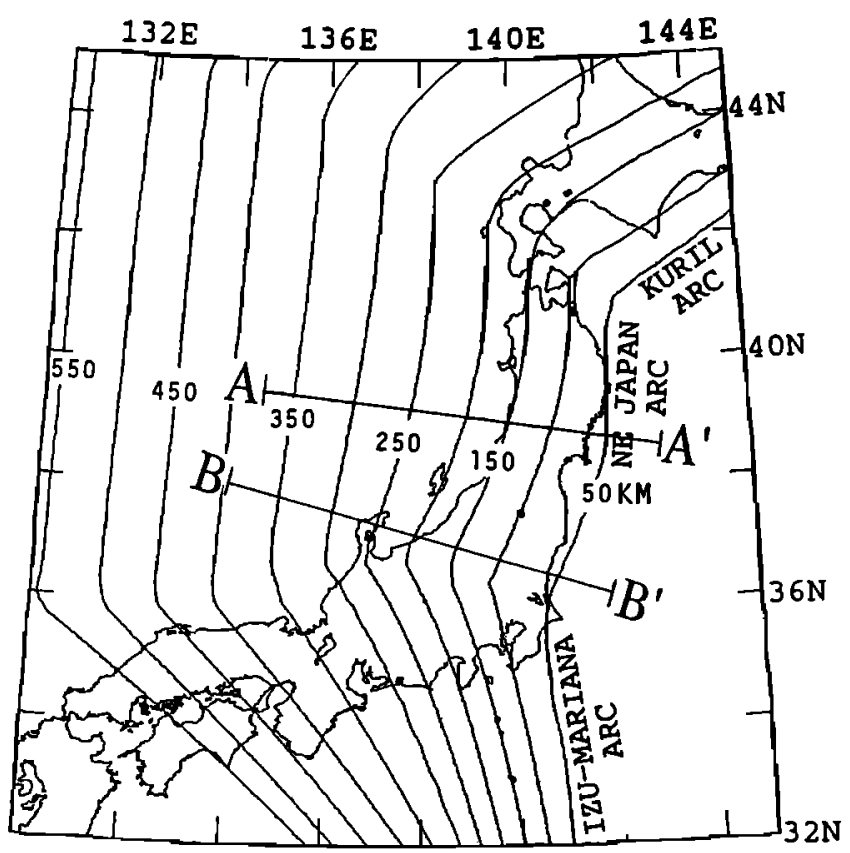

Figure 6. Depth distribution of the upper boundary of the subducting Pacific plate in and around the Japan Islands [after Zhao and Hasegawa, 1993]. Locations of the cross sections in Figure 9 and Plate 1 are shown.
Tohoku. This was confirmed by conducting a numerical simulation with a model having the geometry of the Pacific plate as that shown in Figure 6 [Zhao and Hasegawa, 1994].

These observations demonstrate that the teleseismic data, independent of the local and regional data, contain a wealth of important information on the deep structure of the Japan Islands.

Following Zhao et al. [1992a] and Zhao and Hasegawa [1993], we conducted two kinds of inversions. The first is free inversions, in which we did not introduce any a priori information into the starting model; the second is constrained inversions, in which the Pacific plate is taken into account in the model.

\section{Free Inversion}

The major aim of the free inversion is to know if and how well we can image the subducting Pacific plate by using the present method and data set. The starting 1-D velocity model for the free inversion is the same as that used by Zhao and Hasegawa [1993]. The medium under study is divided into three layers by the Conrad and the Moho discontinuities. The three layers correspond to the upper crust, lower crust and upper mantle, respectively. The upper crust and lower crust are two constant-velocity layers with a $P$ wave velocity of 6.0 and $6.7 \mathrm{~km} / \mathrm{s}$, respectively. The Conrad and Moho discontinuity are curved surfaces with two-dimensional geometries as shown in Figure 7. This crustal model is determined by inverting a large number of arrival times from shallow earthquakes [Zhao et al., 1992b], and is confirmed to represent well the seismic velocity structure of the crust in the Japan Islands [Zhao et al., 1992b; Zhao and Hasegawa, 1993]. In the upper crust, lower crust and upper mantle, we individually set 1,1 and 16 layers of grid meshes. The separation between grid nodes is $25-35 \mathrm{~km}$ in the horizontal direction and $15-35$ $\mathrm{km}$ in the vertical direction. Figure 8 shows the configuration of the grid mesh in a horizontal plane. The depth and initial velocity of each mesh layer are the same as those used by Zhao and Hasegawa [1993] (see Table 1 in their paper).

Applying our technique to all the local, regional and teleseismic data and adopting the initial velocity model as described above, we performed a tomographic inversion. The teleseismic residuals are corrected for the undulations of the Conrad and Moho discontinuities. Because no plate boundary exists in the model of the free inversion, we did not use the 248 arrival times of converted waves at the plate boundary. We simultaneously solved the inverse problem for $1241 \times 4$ hypocentral parameters and 13,749 velocity perturbations for grid nodes with hit counts (number of rays passing through each grid) larger than 10 . More than $99 \%$ of those grid nodes have hit counts larger than 20 . The root-meansquare (rms) travel time residual is $0.521 \mathrm{~s}$ before the inversion and reduced to $0.375 \mathrm{~s}$ after the inversion. The variance reduction amounts to $48 \%$. Two vertical cross sections of $P$ wave velocity perturbations in percent determined by the free inversion are shown in Figures $9 \mathrm{a}$ 


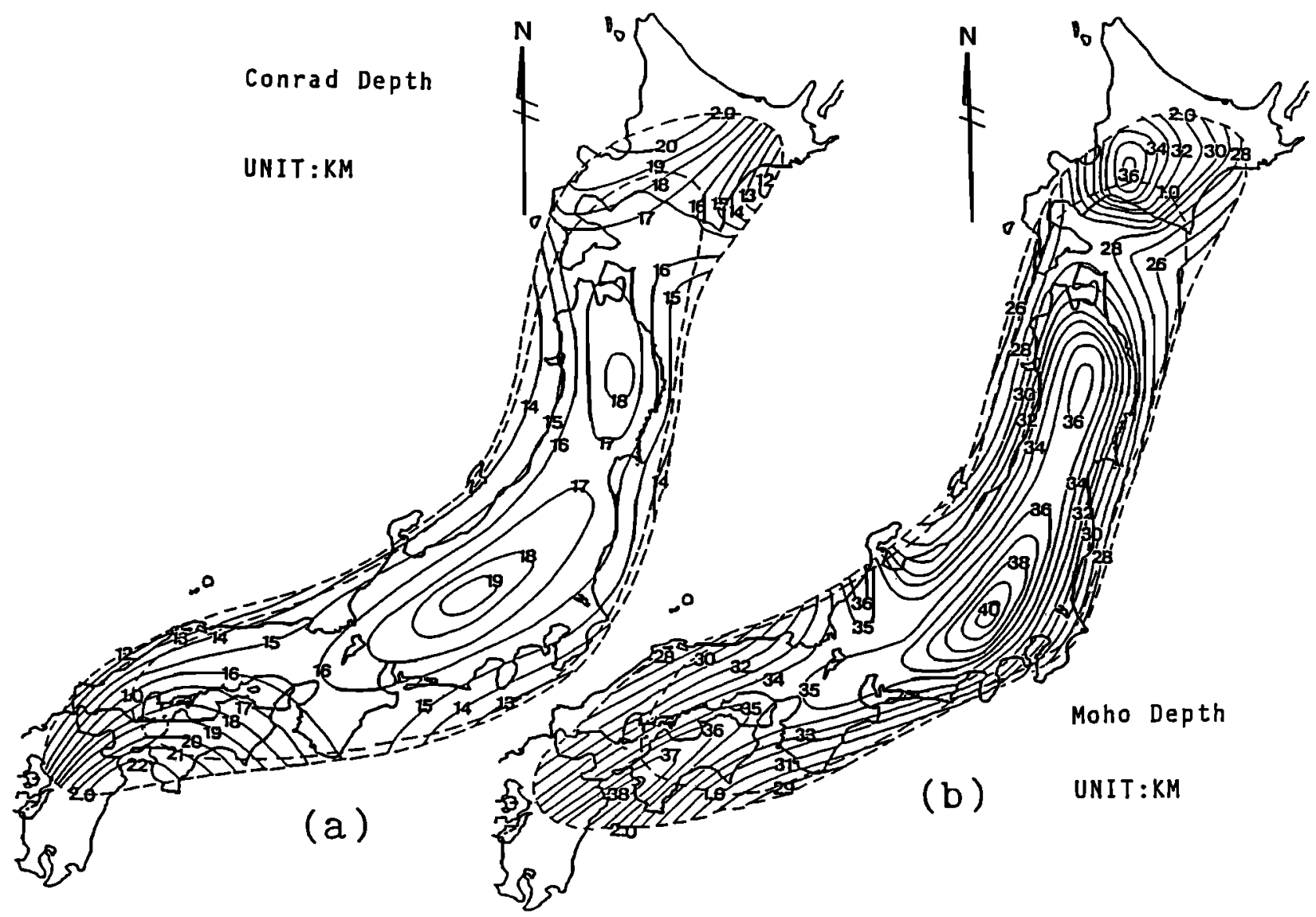

Figure 7. Depth distribution of (a) the Conrad and (b) the Moho discontinuities [after Zhao et al., 1992b]. Solid lines denote depth contours, dashed lines the standard errors of the estimated depths. The outer dashed line encloses the region where the standard error is less than 2-km, and the inner one less than $1-\mathrm{km}$.

and $9 \mathrm{~b}$. Locations of the cross sections are shown in Figure 6.

For comparison, we also conducted an inversion with the same method and starting model but only used the data from the 1241 local and regional events. The result is shown in Figures 9c and 9d along the same profiles as Figures 9a and 9b. We can see that the images for the crust, mantle wedge and the slab in Figures $9 \mathrm{c}$ and 9d are very similar to those in Figures $9 \mathrm{a}$ and $9 \mathrm{~b}$. The differences are in areas around the lower plate boundary and the mantle below the plate. Note that by just using the local and regional data, we have achieved a much better image of the high-velocity Pacific slab than that by Zhao and Hasegawa [1993] (this can be seen by comparing Figure $8 \mathrm{~b}$ in their paper with the present Figure $9 c)$. The major reason for this difference is considered to be the $\mathbf{4 1}$ deep earthquakes we added in the present data set. Zhao and Hasegawa [1993] used too few deep events to image the slab well with the free inversion.

With the addition of the teleseismic data, although the tomographic images for the crust, mantle wedge and the slab have changed little, the images are determined more reliably, especially for the area around the lower plate boundary and the mantle below the plate (see the resolution analyses as described in the following sec- tion). This improvement of the slab image is easy to understand. The teleseismic rays propagate basically in a vertical direction. They crisscross with the horizontally propagating rays from the deep events in the slab, resulting in good coverage of rays around the slab and the mantle below the slab. We can see in Figure 9 that a continuous high-velocity zone is clearly visible from 50 to $400-500 \mathrm{~km}$ in the two cross sections. The slablike zone has a thickness of $70-100 \mathrm{~km}$ and a $P$ wave velocity $2-6 \%$ higher than the normal mantle.

The improved slab image in Figure 9, however, is still not very satisfactory. The upper and lower boundaries of the high-velocity zone show a sawtooth shape. Relatively low velocity anomalies are visible in some areas within the high-velocity zone corresponding to the $\mathrm{Pa}$ cific plate. The high-velocity zone is even broken by the low-velocity anomalies in several places. Obviously, the images in Figure 9 do not show the real form of the slab but just its obscure picture because of the imperfect resolution and parameterization of the free inversions.

\section{Constrained Inversion}

There are at least three reasons which motivated us to conduct the constrained inversions in which we introduced the high-velocity Pacific plate into the model. 


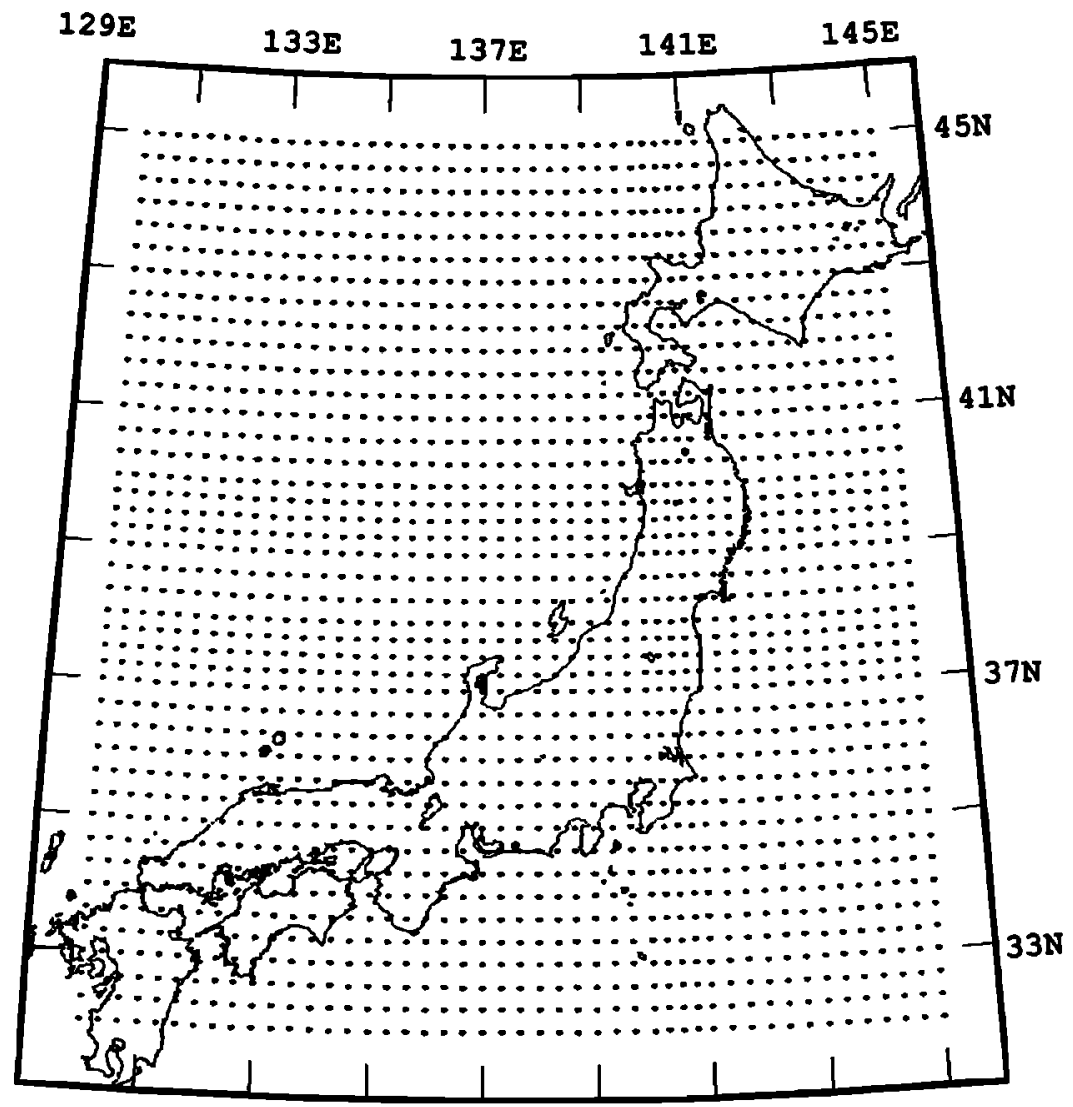

Figure 8. Configuration of the grid net in a horizontal plane.

First, by detecting and analyzing converted and reflected waves, many previous researchers have demonstrated the existence of the upper boundary of the Pacific plate and found that the boundary is a very sharp seismic velocity discontinuity with a complex geometry. For reviews, see Zhao [1991], Zhao and Hasegawa [1993], and Hasegawa et al. [this issue]. Second, without taking into account the plate boundary in the model, we cannot calculate accurately ray paths and travel times for long rays from deep events, and therefore the final tomographic image, especially those near the discontinuities, will be distorted [Zhao, 1991; Koketsu, 1991; Zhao and Hasegawa, 1993]. Third, later phases such as the reflected and converted waves at the plate boundary, which are frequently observed in Japan, cannot be used in the tomographic inversions if the plate boundary is not introduced into the model. Later phases contain very important information on the interior structure of the Earth, especially the structure close to the discontinuities. When later phases are used, hypocenters can be located more accurately and ray coverage can be improved because their trajectories are quite different from those of first arrivals.

Following Zhao and Hasegawa [1993], we adopt a velocity model as shown in Figure 10 in the constrained inversions. The medium under study is divided into four layers by the Conrad, the Moho and the upper boundary of the subducting Pacific plate. The four layers correspond to the upper crust, lower crust, mantle wedge and the mantle below the plate boundary. The geometries of the Conrad and the Moho are the same as those shown in Figure 7. We take the depth distribution of the upper boundary of the subducting Pacific plate as that shown in Figure 6, which is constructed by Zhao and Hasegawa [1993] by referring to the studies using later arrivals and accurate hypocentral locations of deep earthquakes. In the four layers, we individually set $1,1,16$ and 16 layers of grid meshes, which are the same as those of Zhao and Hasegawa [1993] (see Table 1 in their paper). The configuration of the grid mesh is shown in Figure 8.

From the result of the free inversion (Figure 9), we can see that the subducting Pacific plate has a thickness of $70-100 \mathrm{~km}$ and a $P$ wave velocity $2-6 \%$ higher than the normal mantle. Therefore in the constrained inversion, we assign the initial thickness and velocity of the plate to be $85-\mathrm{km}$ and $4 \%$ high, respectively. Applying our method to all the local, regional and teleseismic data and adopting the initial model as shown in Figure 10, we performed a constrained inversion. In this inversion we used all the later arrivals in addition to first arrivals. We solved the problem simultaneously for $1241 \times 4$ hypocentral parameters and 16,061 velocity perturbations for grid nodes with hit counts larger than 10. The rms travel time residual is $0.421 \mathrm{~s}$ before the inversion and reduced to $0.353 \mathrm{~s}$ after the inversion.

Two vertical cross sections of $P$ wave velocity perturbations determined by the constrained inversion are shown in Plates 1a and 1b. A map view of the tomographic image at four depth levels is shown in Plate 2. 


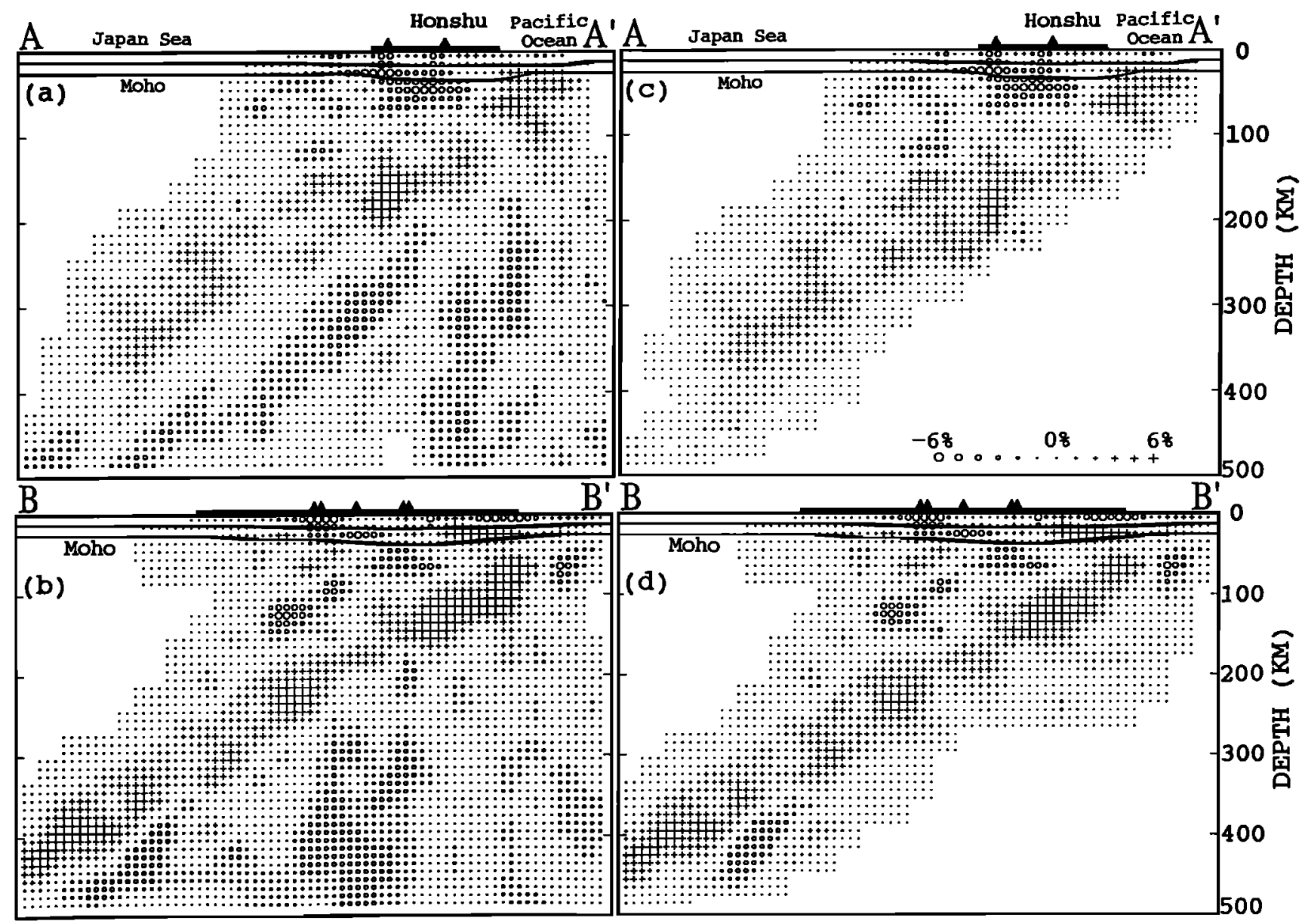

Figure 9. ( $a$ and b) Vertical cross sections of fractional $P$ wave velocity perturbations (in percent) obtained by the free inversion (see text for details). Local, regional and teleseismic data are all used in the inversion. ( $c$ and d) Same as Figures 9a and $9 \mathrm{~b}$ but only the data from local and regional events are used in the inversion. Cross and circle denote high and low velocities, respectively. The perturbation scale is shown in Figure 9c. The land area and active volcanoes are shown at the top of each figure by the bold horizontal lines and solid triangles, respectively. Locations of the cross sections are shown in Figure 6.

For comparison, we also conducted a constrained inversion using local and regional data only. The result is shown in Plates 1c and 1d along the same profiles as Plates $1 \mathrm{a}$ and $1 \mathrm{~b}$. We can see that the images in Plate

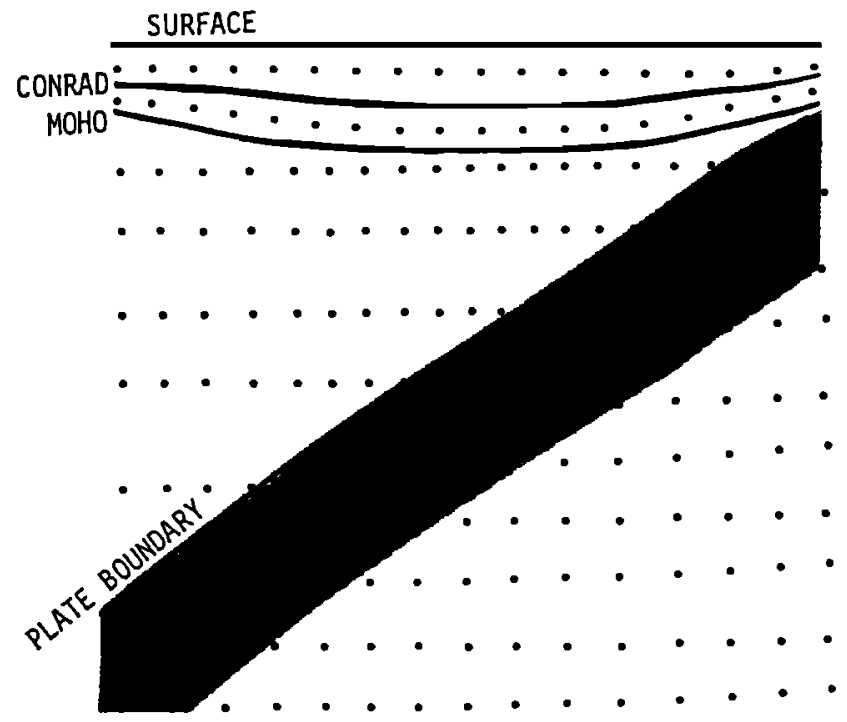

1 are, as a whole, similar to those in Figure 9. The images of the crust, mantle wedge and slab in Plates 1c and $1 \mathrm{~d}$ are very similar to those in Plates $1 \mathrm{a}$ and $1 \mathrm{~b}$. However, the result for the area around and below the lower boundary of the slab in Plates $1 \mathrm{c}$ and $1 \mathrm{~d}$ is less reliable. With the addition of the teleseismic data, the structure of the mantle around and below the slab is determined much more reliably because the ray coverage there is dramatically improved.

We also conducted a number of constrained inversions by changing the initial thickness and initial velocity of the Pacific slab. We found that although some variations occur in the amplitudes of velocity anomalies, the pattern of the tomographic image as shown in Plates 1 and 2 exhibits almost no change when the initial slab thickness is in the range of $10-120 \mathrm{~km}$ and the initial

Figure 10. Schematic illustration of the seismic velocity model adopted for the constrained inversion (see text for details). Dots denote grid nodes of 3-D grid nets individually set in the four layers. Hatched area denotes the subducting Pacific plate. 


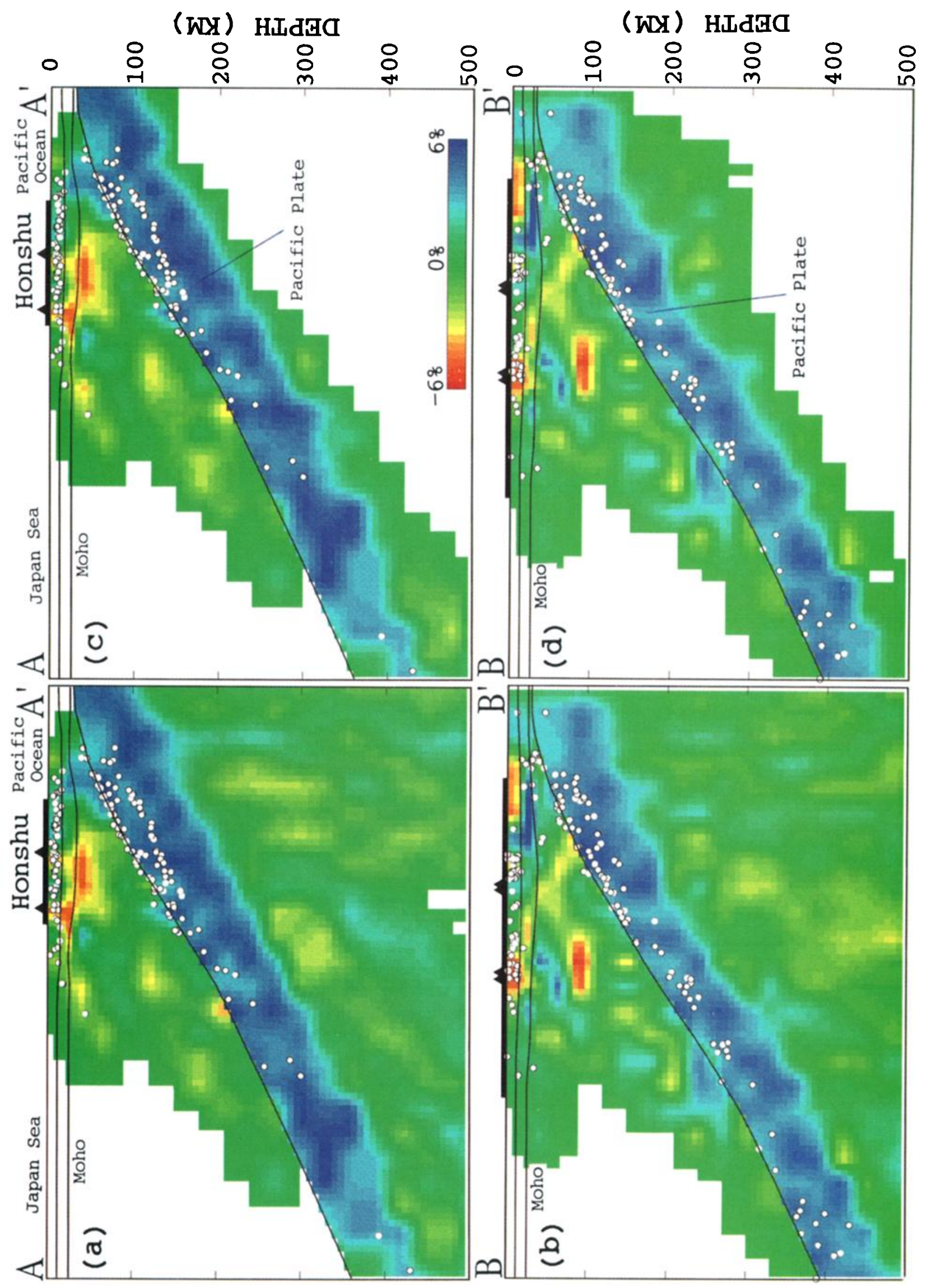




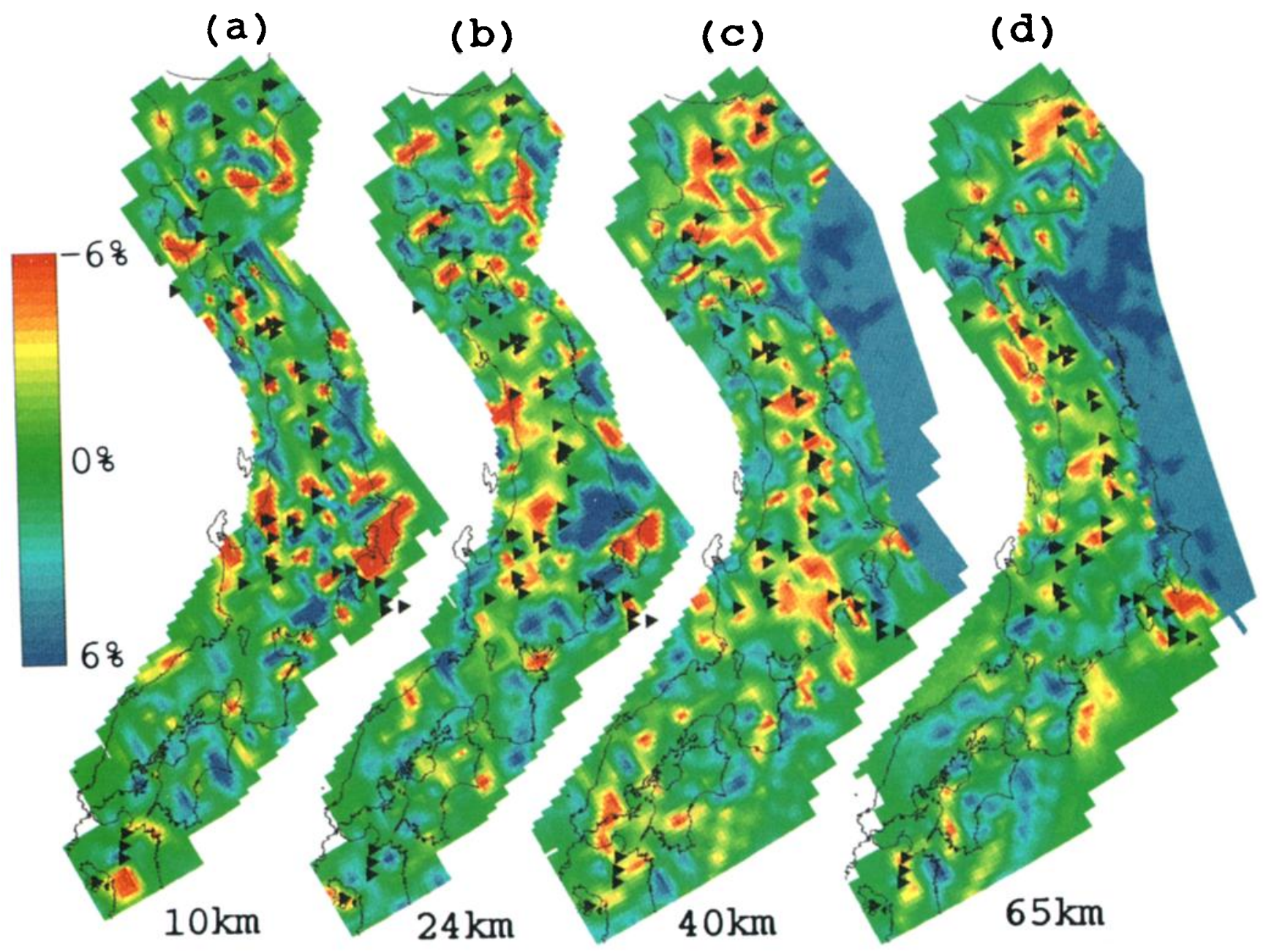

Plate 2. Fractional $P$ wave velocity perturbations (in percent) at four depths determined by the constrained inversion (see text): (a) 10-km, (b) 24-km, (c) 40-km, (d) 65-km. Red and blue denote low and high velocities, respectively. The perturbation scale is shown on the left of the figure. Solid triangles denote active volcanoes in the Japan Islands.

slab velocity is $1-7 \%$. These tests indicate that the final tomographic image is well constrained by the whole data set from local, regional and teleseismic events, and does not depend on the initial model very much.

The final rms residual of the constrained inversion $(0.353 \mathrm{~s})$ is smaller than that of the free inversion $(0.375$ s). To know if this rms residual reduction is statistically significant or not, we used the $F$ test [Draper and Smith, 1966]. A detailed explanation of the application of the $F$ test to tomographic models can be found in the work by Zhao and Hasegawa [1993]. Through some simple calculations, we found that the decrease in the rms residual for the constrained inversion is surely sig- nificant from a statistical point of view. Therefore we prefer the result obtained by the constrained inversion and take it as our final result.

\section{Resolution and Result}

We have used the method of checkerboard resolution test to assess the adequacy of the ray coverage and to evaluate the resolution. For details of the method, see Humphreys and Clayton [1988], Inoue et al. [1990], and Zhao and Hasegawa [1993]. Figure 11 shows the result of a checkerboard resolution test with a grid separation of 33-km for the velocity model of the constrained in-

Plate 1. (a and b) Vertical cross sections of fractional $P$ wave velocity perturbations (in percent) obtained by the constrained inversion (see text for details). Local, regional and teleseismic data are all used in the inversion. ( $c$ and d) Same as Plates 1a and 1b but only the data from local and regional events are used in the inversion. Blue and red denote high and low velocities, respectively. The perturbation range is shown in Plate 1c. The land area and active volcanoes are shown at the top of each figure by the bold horizontal lines and solid triangles, respectively. Open circles denote earthquakes which are used in this study and occurred within a 80-km width along the profiles. Locations of the cross sections are shown in Figure 6. 


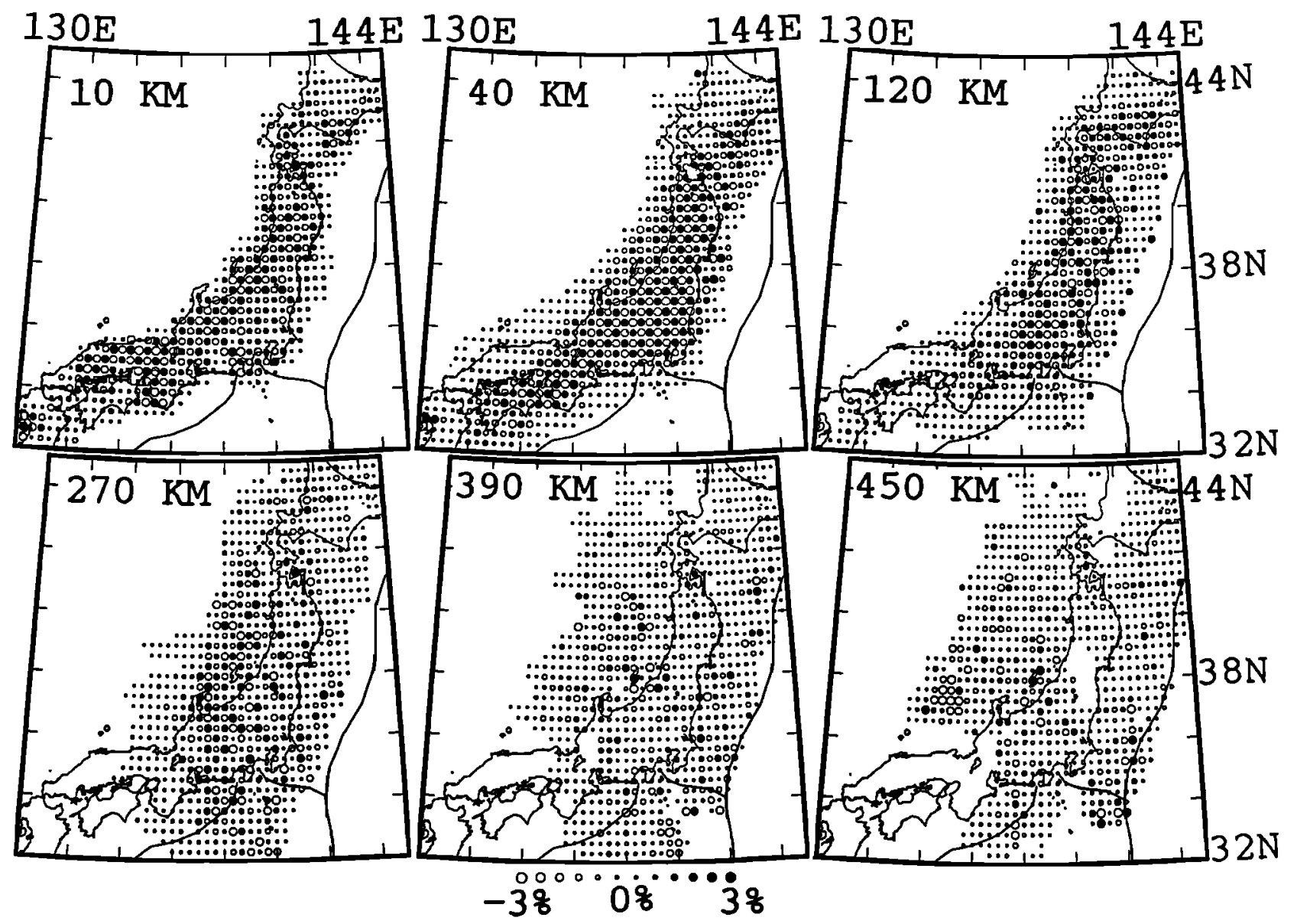

Figure 11. Result of a checkerboard resolution test (see text) for six typical layers. The depth of each layer is shown at the upperleft corner of the map. The grid separation in this test is $33-\mathrm{km}$. Solid and open circles denote high and low velocities, respectively. The scale is shown at the bottom of the figure.

version. The resolution is generally high in the central part of the study area, which is expected. It is generally good for the layers shallower than $250-\mathrm{km}$. In the deeper areas corresponding to the subducting Pacific plate, the resolution is generally good and the pattern is, on the whole, correctly reconstructed. At the edge and deepest part of the study area, the pattern of the checkerboard is not correctly reconstructed. Figure 12 shows the result of another checkerboard resolution test with a grid separation of $50-\mathrm{km}$. We can see in Figure 12 that the resolution is high and the checkerboard pattern is correctly reconstructed for most of the study area.

From the two resolution tests, we can say that the tomographic image obtained in the present study has a spatial resolution of about 33-km for the upper $250-\mathrm{km}$ depths and 33-50 km for the deeper areas. Note that the resolution, as a whole, becomes better than that of the result determined by Zhao and Hasegawa [1993] (see Figures 12 and 13 in their paper), especially for the area around the lower plate boundary and the mantle below the plate.

The structure of the crust and the shallower portion of the upper mantle is very similar to that by Zhao and Hasegawa [1993] (see Plates 1 and 2). Large regional variations exist in the crustal velocity structure between western and eastern Japan. The velocity under western Japan except Kyushu is generally high and relatively homogeneous, in contrast with an average lower velocity and a significant inhomogeneity beneath eastern Japan, where many active volcanoes exist. This pattern is consistent with the distribution of the horizontal gradient of the gravity anomaly in Japan determined by Kono and Furuse [1989] (see also Figure 16 in Zhao and Hasegawa [1993]). In Hokkaido and eastern Honshu, low-velocity zones are distributed in and around active volcanoes. In addition to the volcanic areas, low-velocity anomalies in the upper crust are also present near Urakawa in Hokkaido and around Tokyo Bay in the Kanto District (see Figure 1 for the locations of the two areas). This is consistent with previous studies by Miyamachi and Moriya [1984], Horie and Aki [1982], and Ishida and Hasemi [1988]. The low-velocity zones in the two areas correspond to the thick Quaternary sedimentary layers there.

Low-velocity anomalies amounting to $6 \%$ are continuously distributed to a depth of about $200-\mathrm{km}$ in the mantle wedge along the volcanic front from Hokkaido to Kanto-Tokai. The low-velocity zones dip toward the west and are generally parallel with the high-velocity Pacific plate (see Plate 1). In Kyushu, low-velocity 


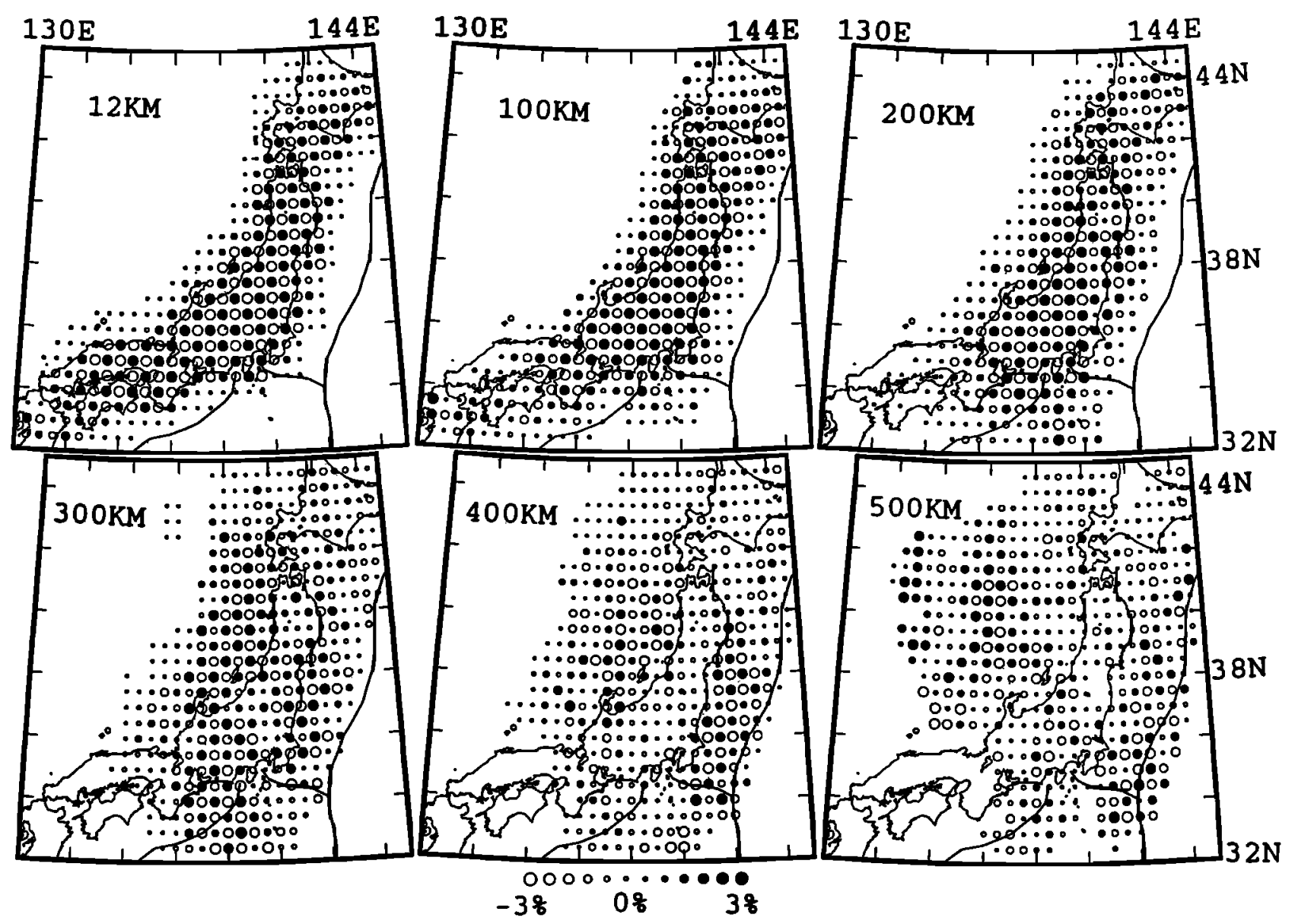

Figure 12. Result of a checkerboard resolution test (see text) for six typical layers. The depth of each layer is shown at the upperleft corner of the map. The grid separation in this test is $50-\mathrm{km}$. Solid and open circles denote high and low velocities, respectively. The scale is shown at the bottom of the figure.

zones are also present beneath active volcanoes and extend to the upper mantle (see also Figure $9 \mathrm{~b}$ of Zhao and Hasegawa [1993]).

The subducting Pacific plate has $P$ wave velocities 4-6\% higher than the surrounding mantle. In the tomographic image, we can see that the thickness of the plate changes slightly at different depths, but in the range of $80-90 \mathrm{~km}$ (see Plate 1). Within the Pacific plate the $P$ wave velocity has variations of about $2 \%$. In a previous study of tomographic images in northeastern Japan, Zhao et al. [1992a] found in a map view that most earthquakes in the lower plane of the double seismic zone occur in relatively high-velocity areas of the plate for areas shallower than $200-\mathbf{k m}$. Note that the double seismic zone exists from 60 - to $200-\mathrm{km}$ depth in northeastern Japan; the two seismic planes merge to a single plane below 200-km depth [Hasegawa et al., this issue]. For details of the correlation between the lower plane seismicity and velocity variations within the slab, see Figure 18 of Zhao et al. [1992a]. This feature is also found in the present result for the northeastern Japan. The seismic velocity structure of the Japan subduction zone determined by this study is generally consistent with the temperature models [e.g., Toksoz et al., 1971; Furukawa, 1993].
Plate 1 shows that the upper boundary of the slab bends upwards below about $200-\mathrm{km}$ depth, while this feature does not show up in the result of the free inversions (Figure 9). The geometry of the plate boundary we adopted here (Figure 6) is mainly determined from the distribution of deep earthquakes. We do not think that the seismicity alone can define this small bending curvature change, and therefore this feature is considered to be meaningless. We have conducted a number of inversions by taking into account the small curvature change of the plate boundary, and found that this small curvature change has almost no effect on the result we obtained.

In the mantle below the slab, we can see some velocity anomalies which have spatial extents of about $100-\mathrm{km}$ or larger and $P$ wave velocities 2-3\% lower than that of the normal mantle. Taking into account the resolution scale in that area $(33-50 \mathrm{~km})$, we consider that these lower-velocity anomalies are real features, but not the artifacts of the inversion due to the lack of resolution. We will discuss these anomalies in more detail in the following section.

\section{Discussion}

So far, two kinds of travel time tomographic studies have been actively conducted, one using data from 
local and regional earthquakes, originated by $A k i$ and Lee [1976], the other using teleseismic residuals, originated by $A k i$ et al. [1977]. The two methods have inherent advantages and drawbacks. The local and regional tomography can determine the shallow structure of an area to a depth above which earthquakes exist or the diving rays (like $P n$ ) propagate, but cannot determine the deeper structure. In contrast, teleseismic tomography can determine the deep structure of an area (the modeling depth depends on the aperture of the array used), but usually cannot determine well the shallow structure simply because teleseismic rays basically travel in a vertical direction and do not crisscross well near the surface. In this study, we conducted tomographic inversions by using the data from local, regional and teleseismic events simultaneously, which preserves the advantages of the two separate approaches and overcomes their drawbacks. The successful applications of the joint inversion method in this study demonstrate the power of this new approach.

In this study, we used the teleseismic data collected only from the stations in northeastern Japan because we could only access the seismograms recorded by the seismic network of Tohoku University. If teleseismic data from all the JUNEC stations in the entire Japan Islands will be available in the future, we will be able to extend the modeling space to the lower mantle because the aperture of the array is greatly enlarged. Thus we may determine the structure around the $650-\mathrm{km}$ discontinuity and get some information on the slab penetration in the mantle beneath Japan. With teleseismic data from stations in southwestern Japan, we may also determine the structure of the Philippine Sea plate well. The seismicity associated with the subduction of the young Philippine Sea plate exists at depths shallower than $1120-\mathrm{km}$ in southwestern Japan. One interesting and important question is how deep the Philippine Sea plate penetrates beneath this area. Does it just reach the depth of the deepest seismicity or penetrate to a greater depth aseismically? A joint tomographic inversion of local and teleseismic data as adopted in this study may help to solve this problem. This kind of application has been made for the Alaska subduction zone, and a promising result obtained [Zhao et al., 1993].

We found that in the Japan subduction zone, prominent low-velocity anomalies exist in the crust and mantle wedge above the subducting Pacific plate, and the low-velocity anomalies seem to be associated with the volcanism in the island arc [Hasegawa et al., 1991; Zhao et al., 1992a]. Similar structures have been found in many other subduction zones in the world, e.g., Aleutians [Engdahl and Gubbins, 1987], Alaska [Zhao et al., 1992c, 1993], Cascadia [Michaelson and Weaver, 1986; Rasmussen and Humphreys, 1988; Zhao et al., 1992d], Caribbean [van der Hilst and Engdahl, 1991], Tonga, Kermadec and Hebrides [Zhou, 1990], New Zealand [Kuge and Satake, 1987; Satake and Hashida, 1989], Indonesia [Puspito et al., 1993], Mediterranean [Spakman et al., 1993], and Taiwan [Roecker et al., 1987]. Although the resolution scale is different for each of the results, all of them show low velocities beneath volcanoes in the crust and mantle wedge. We consider that this feature (volcanism-related low-velocity anomalies in the crust and mantle wedge) is a common seismological characteristic of subduction zones. Through numerical calculations with a two-dimensional viscous flow model, Furukawa [1993] suggested that the temperature structures and stress fields in the crust and mantle wedge are all similar under various island arcs, and independent of the subduction parameters such as the angle and speed of slab subduction, the temperature structures of the slab and back-arc region, and the thickness of the overlying lithosphere. This seems a good explanation of the seismological observations.

Our tomographic result shows that the prominent low-velocity zones in the mantle wedge extend continuously from the Moho discontinuity to a depth of approximately $200-\mathrm{km}$ beneath Japan. This is consistent with petrological and geochemical studies. Geochemists have suggested that a key factor of magmatism in island arcs is the aqueous fluids dehydrated from the subducting slab [Boettcher, 1977; Sakuyama and Nesbitt, 1986]. From the results of high-temperature and high-pressure experiments under wet conditions, Tatsumi [1989] suggested that amphibolite, chlorite, phlogopite, talc, and serpentine are major hydrous minerals in the mantle wedge. The temperature at the upper surface of the slab is about $800^{\circ} \mathrm{C}$ at depths greater than $100-\mathrm{km}[F u-$ rukawa, 1993]. Under these temperature and pressure conditions, these hydrous minerals, which are carried deeper by the downward induced flow in the mantle wedge, will break down at depths shallower than 200$\mathrm{km}$, which is the stability limit of phlogopite [Tatsumi, 1989]. The termination of dehydration in the subducting oceanic crust is essentially defined by the stability limit of hornblende, which is about $100-\mathrm{km}$. The temperature of the upper surface of the slab will change a little with the age of the slab. Thus the major dehydration reactions are considered to take place at depths shallower than $200-\mathrm{km}$ in the mantle wedge. Aqueous fluids released from these hydrous minerals will move upward because of buoyancy; the migration mechanism may be the buoyancy-driven fracturing for magma migration under island arcs [Furukawa, 1993].

The existence of lower-velocity anomalies in the mantle below the subducted Pacific slab in and around Japan has been suggested by previous tomographic studies, e.g., Zhou and Clayton [1990], van der Hilst et al. [1991], and Fukao et al. [1992], who used the data reported in the Bulletin of the International Seismological Centre (ISC) and determined tomographic images with a spatial resolution scale of $100-\mathrm{km}$ or larger. The subslab low-velocity anomalies show different images, which might be caused by variations in the study area, data set, analysis method, and resolution scale in each of the studies. The tomographic image beneath Japan determined by the present study has a much higher resolution than that of all the previous studies using the ISC data set and therefore is believed to be more reliable. It is unclear how the subslab lower-velocity anomalies 
are formed. One possibility is that they are associated with small-scale mantle convections. The subduction of the oceanic plate probably generates a secondary mechanically induced convection in the overlying mantle wedge [e.g., Mckenzie, 1969; Sleep and Toksoz, 1973; Toksoz and Bird, 1977]. The subducting slab is not a simple planar plate, but has a complex geometry in both strike and dip directions. As a result, a similar mechanically induced convection may be also generated in the mantle below the slab by the subduction of the oceanic plate, which results in the lateral variation of density and/or temperature, and therefore causes the lateral heterogeneities of seismic velocity. Another possibility is that the lower-velocity anomalies below the slab show the image of mantle plumes arising from the deep interior of the Earth, e.g., from the $650-\mathrm{km}$ discontinuity and/or the core-mantle boundary. To clarify this problem, further high-resolution tomographic studies are needed in this region and other subduction zones. Geodynamic studies in both theoretical and experimental aspects will also be helpful.

\section{Conclusions}

We simultaneously used a large number of high accuracy data from local, regional and teleseismic events to determine a detailed three-dimensional $P$ wave velocity structure of the Japan subduction zone to a depth of $500-\mathrm{km}$. The subducting Pacific plate is clearly imaged by a free inversion without any a priori constraint on the slab in the starting model. However, constrained inversions are found to give a result which explains the whole data set better. Compared with previous results obtained from only local and regional events, the present result has a much higher resolution for the area around the lower boundary of the Pacific plate and the mantle below the plate, thanks to the addition of 7035 data from 100 teleseismic events and 41 very deep earthquakes. Prominent low-velocity anomalies exist in the crust and upper mantle beneath active volcanoes. In the mantle wedge the low-velocity anomalies dip toward the west and extend continuously to a depth of about 200-km, which is consistent with petrological, geochemical and geodynamic studies. We believe that the existence of the volcanism-related mantle wedge low-velocity anomalies is a common seismological feature of subduction zones, in light of all the available tomographic results for many subduction regions in the world. The subducting Pacific plate beneath Japan is imaged well as a high-velocity zone with a thickness of $80-90 \mathrm{~km}$ and a $P$ wave velocity $4-6 \%$ higher than the normal mantle. Lower-velocity anomalies are visible in the mantle below the slab.

Acknowledgments. We used arrival times reported in the Japan University Network Earthquake Catalog published by the Earthquake Research Institute, University of Tokyo. We thank the staff members of the seismic networks of Hokkaido University, Hirosaki University, and University of Tokyo for allowing us to use the teleseismic data recorded at some of their stations. We thank K. Aki and D. L. Anderson for fruitful discussions. H. Zhou, C. Finn, K. Suyehiro, and two anonymous referees critically read the manuscript and provided us with helpful comments, which improved the manuscript. This work was partially supported by a $\mathrm{Na}$ tional Science Foundation grant, EAR-92-04748. The first author (D.Z.) has been supported by a fellowship from the Southern California Earthquake Center and the Texaco Research Fellowship from the California Institute of Technology. Division of Geological and Planetary Sciences, California Institute of Technology, Contribution No. 5300 .

\section{References}

Aki, K., and W. H. K. Lee, Determination of three dimensional velocity anomalies under a seismic array using first $P$ arrival times from local earthquakes, 1 , A homogeneous initial model, J. Geophys. Res., 81, 4381-4399, 1976.

Aki, K., A. Christoffersson, and E. S. Husebye, Determination of the three-dimensional seismic structure of the lithosphere, J. Geophys. Res., 82, 277-296, 1977.

Boettcher, A. L., The role of amphiboles and water in circum-Pacific volcanism, in High-Pressure Research: Applications in Geophysics, edited by M. H. Manghnani and S. Akimoto, pp. 107-126, Academic, San Diego, Calif., 1977.

Draper, N. R., and H. Smith, Applied Regression Analysis, John Wiley, New York, 1966.

Engdahl, E. R., and D. Gubbins, Simultaneous travel time inversion for earthquake location and subduction zone structure in the central Aleutian Islands, J. Geophys. Res., 92, 13,855-13,862, 1987.

Fukao, Y., M. Obayashi, H. Inoue, and M. Nenbai, Subducting slabs stagnant in the mantle transition zone, $J$. Geophys. Res., 97, 4809-4822, 1992.

Furukawa, Y., Magmatic processes under arcs and formation of the volcanic front, J. Geophys. Res., 98, 8309-8319, 1993.

Hasegawa, A., N. Umino, and A. Takagi, Double-planed deep seismic zone and upper-mantle structure in the northeastern Japan arc, Geophys. J. R. Astron. Soc., 54, 281$296,1978$.

Hasegawa, A., D. Zhao, S. Hori, A. Yamamoto, and S. Horiuchi, Deep structure of the northeastern Japan arc and its relationship to seismic and volcanic activity, Nature, 352, 683-689, 1991.

Hasegawa, A., S. Horiuchi, and N. Umino, Seismic structure of the northeastern Japan convergent margin: A synthesis, J. Geophys. Res., this issue.

Herman, G. T., Image Reconstruction from Projections: The Fundamentals of Computerized Tomography, 316 pp., Academic, San Diego, Calif., 1980.

Hisamoto, S., On the anomaly of travel time of $S$ waves observed in eastern Japan, 1 (in Japanese), J. Seismol. Soc. Jpn., 18, 142-153, 1965a.

Hisamoto, S., On the anomaly of travel time of $S$ waves observed in eastern Japan, 2 (in Japanese), J. Seismol. Soc. Jpn., 18, 195-203, 1965b.

Horie, A., and K. Aki, Three-dimensional velocity structure beneath the Kanto District, Japan, J. Phys. Earth, 30, 255-281, 1982.

Humphreys, E., and R. W. Clayton, Adaptation of back projection tomography to seismic travel time problems, J. Geophys. Res., 99, 1073-1085, 1988.

Inoue, H., Y. Fukao, K. Tanabe, and Y. Ogata, Whole mantle $P$ wave travel time tomography, Phys. Earth Planet. Inter., 59, 294-328, 1990.

Ishida, M., and A. H. Hasemi, The three-dimensional fine 
velocity structure and hypocentral distribution of earthquakes beneath the Kanto-Tokai District, Japan, J. Geophys. Res., 93, 2076-2094, 1988.

Kanamori, H., Travel time to Japanese stations from Longshot and their geophysical implications, Bull. Earthquake Res. Inst. Univ. Tokyo, 46, 841-859, 1968.

Katsumata, M., The effect of seismic zone upon the transmission of seismic waves (in Japanese), Q. J. Seismol., 25, 89-95, 1960.

Kennett, B. L. N., and E. R. Engdahl, Traveltimes for global earthquake location and phase identification, Geophys. $J$. Int., 105, 429-465, 1991.

Kono, Y., and N. Furuse, 1:1 Million Scale Gravity Anomaly Map in and Around the Japanese Islands, University of Tokyo Press, Tokyo, 1989.

Koketsu, K., Three-dimensional ray tracing in a subduction zone (in Japanese with English abstract), J. Seismol. Soc. Jpn., 44, 165-176, 1991.

Kuge, K., and K. Satake, Lateral segmentation within the subducting lithosphere: Three-dimensional structure beneath the North Island, New Zealand, Tectonophysics, 139, 223-237, 1987.

Lees, J. M., and R. S. Crosson, Tomographic inversion for three-dimensional velocity structure at Mount St. Helens using earthquake data, J. Geophys. Res., 94, 5716-5729, 1989.

Matsuzawa, T., N. Umino, A. Hasegawa, and A. Takagi, Upper mantle velocity structure estimated from $P S$-converted wave beneath the northeastern Japan arc, Geophys. J. $R$. Astron. Soc., 86, 767-787, 1986.

Matsuzawa, T., T. Kono, A. Hasegawa, and A. Takagi, Subducting plate boundary beneath the northeastern Japan arc estimated from $S P$ converted waves, Tectonophysics, 181, 123-133, 1990.

Mckenzie, D. E., Speculations on the consequences and causes of plate motions, Geophys. J. R. Astron. Soc., 18, 1-32, 1969.

Michaelson, C. A., and C. S. Weaver, Upper mantle structure from teleseismic $\boldsymbol{P}$ wave arrivals in Washington and Northern Oregon, J. Geophys. Res., 91, 2077-2094, 1986.

Miyamachi, H., and T. Moriya, Velocity structure beneath the Hidaka Mountains in Hokkaido, Japan, J. Phys. Earth, 32, 13-42, 1984.

Nolet, G., Solving or resolving inadequate and noisy tomographic systems, J. Comput. Phys., 61, 463-482, 1985.

Obara, K., Regional extent of the $S$ wave reflector beneath the Kanto district, Japan, Geophys. Res. Lett., 16, 839$842,1989$.

Obara, K., and H. Sato, Existence of an $S$ wave reflector near the upper plane of the double seismic zone beneath the southern Kanto district, Japan, J. Geophys. Res., 93, $15,037-15,045,1988$.

Okada, H., Forerunners of $S c S$ waves from nearby deep earthquakes and upper mantle structure in Hokkaido (in Japanese), J. Seismol. Soc. Jpn., 24, 228-239, 1971.

Okada, H., New evidence of the discontinuous structure of the descending lithosphere as revealed by $S c S p$ phase, $J$. Phys. Earth, 27, Suppl., S53-S64, 1979.

Paige, C. C., and M. A. Saunders, LSQR: An algorithm for sparse linear equations and sparse least squares, Assoc. Comput. Mach. Trans. Math. Software, 8, 43-71, 1982.

Pavlis, G. L., and J. R. Booker, The mixed discrete continuous inverse problem: Application to the simultaneous determination of earthquake hypocenters and velocity structure, J. Geophys. Res., 85, 4801-4810, 1980.

Puspito, N. T., Y. Yamanaka, T. Miyatake, K. Shimazaki, and K. Hirahara, Three-dimensional $P$-wave velocity structure beneath the Indonesian region, Tectonophysics, 220, 175-192, 1993.
Rasmussen, J., and E. Humphreys, Tomographic image of the Juan de Fuca plate beneath Washington and western Oregon using teleseismic $P$-wave travel times, Geophys. Res. Lett., 15, 1417-1420, 1988.

Roecker, S. W., Y. H. Yeh, and Y. B. Tsai, Three-dimensional $P$ and $S$ wave velocity structure beneath Taiwan: Deep structure beneath an arc-continent collision, $J$. Geophys. Res., 92, 10,547-10,570, 1987.

Sakuyama, M., and R. W. Nesbitt, Geochemistry of the Quaternary volcanic rocks of the northeast Japan arc, $J$. Volcanol. Geotherm. Res., 29, 413-450, 1986.

Satake, K., and T. Hashida, Three-dimensional attenuation structure beneath North Land, New Zealand, Tectonophysics, 159, 181-194, 1989.

Sleep, N., and M. N. Toksoz, Evolution of marginal basins, Nature, 233, 548-550, 1973.

Spakman, W., and G. Nolet, Imaging algorithms, accuracy and resolution in delay time tomography, in Mathematical Geophysics, edited by N. J. Vlaar, G. Nolet, M. J. R. Wortel, and S. A. P. L. Cloetingh, pp. 155-187, D. Reidel, Norwell, Mass., 1988.

Spakman, W., S. van der Lee, and R. van der Hilst, Travel time tomography of the European-Mediterranean mantle down to $1400 \mathrm{~km}$, Phys. Earth Planet. Inter., 79, 3-74, 1993.

Spencer, C., and D. Gubbins, Travel-time inversion for simultaneous earthquake location and velocity structure determination in laterally varying media, Geophys. J. $R$. Astron. Soc., 63, 95-116, 1980.

Tatsumi, Y., Migration of fluid phases and genesis of basalt magmas in subduction zones, J. Geophys. Res., 94, 46974707, 1989.

Toksoz, M. N., and P. Bird, Formation and evolution of marginal basins and continental plateaus, in Island Arcs, Deep Sea Trenches, and Back-Arc Basins, Geophys. Monogr. Ser., Vol. 1, edited by M. Talwani and W. C. Pitman, pp. 379-393, AGU, Washington, D.C., 1977.

Toksoz, M. N., J. W. Minear, and B. R. Julian, Temperature field and geophysical effects of a downgoing slab, J. Geophys. Res., 76, 1113-1138, 1971.

Tsuboi, S., K. Koketsu, K. Takano, T. Miyatake, K. Abe, and Y. Hagiwara, Hypocenter determination procedure of Japan University Network Earthquake Catalog (in Japanese), J. Seismol. Soc. Jpn., 42, 277-284, 1989.

Utsu, T., Anomalies in seismic wave velocity and attenuation associated with a deep earthquake zone, 1, J. Fac. Sci. Hokkaido Univ. Ser. 7 (Geophys.), 3, 1-25, 1967.

Utsu, T., Seismological evidence for the anomalous structure of island arcs with special reference to the Japanese region, Rev. Geophys., 9, 839-890, 1971.

van der Hilst, R., and E. R. Engdahl, On ISC $P P$ and $p P$ data and their use in delay-time tomography of the Caribbean region, Geophys. J. Int., 106, 169-188, 1991.

van der Hilst, R., E. R. Engdahl, W. Spakman, and G. Nolet, Tomographic imaging of subducted lithosphere below northwest Pacific island arcs, Nature, 353, 37-43, 1991.

Wadati, K., On the activity of deep-focus earthquakes in the Japan Islands and neighbourhood, Geophys. Mag., 8, 305-326, 1935.

Zhao, D., A tomographic study of seismic velocity structure in the Japan Islands, Ph.D. thesis, 301 pp., Tohoku Univ., Sendai, Japan, 1991.

Zhao, D., and A. Hasegawa, $P$ wave tomographic imaging of the crust and upper mantle beneath the Japan Islands, J. Geophys. Res., 98, 4333-4353, 1993.

Zhao, D., and A. Hasegawa, Teleseismic evidence for lateral heterogeneities in the northeastern Japan arc, Tectonophysics, in press, 1994.

Zhao, D., S. Horiuchi, and A. Hasegawa, 3-D seismic velocity 
structure of the crust and uppermost mantle in the northeastern Japan arc, Tectonophysics, 181, 135-149, 1990 a.

Zhao, D., S. Horiuchi, and A. Hasegawa, $P$-wave velocity of the uppermost mantle off the Japan Sea coast, Tohoku Geophys. J., 33, 177-183, 1990b.

Zhao, D., A. Hasegawa, and S. Horiuchi, Tomographic imaging of $P$ and $S$ wave velocity structure beneath northeastern Japan, J. Geophys. Res., 97, 19,909-19,928, 1992a.

Zhao, D., S. Horiuchi, and A. Hasegawa, Seismic velocity structure of the crust beneath the Japan Islands, Tectonophysics, 212, 289-301, 1992b.

Zhao, D., D. Christensen, and H. Pulpan, Tomographic imaging of the Alaska subduction zone, Eos Trans. $A G U$, 73, 199, 1992c.

Zhao, D., G. Rogers, and K. Wang, Tomographic imaging of Cascadia subduction zone in and around Vancouver Island, Eos Trans. $A G U, 79,199,1992 \mathrm{~d}$.

Zhao, D., K. Aki, and N. Biswas, How deep does slab penetrate beneath Alaska? Eos Trans. $A G U, 74,312,1993$.
Zhou, H., Mapping of $P$-wave slab anomalies beneath the Tonga, Kermadec and New Hebrides arcs, Phys. Earth Planet. Inter., 61, 199-229, 1990.

Zhou, H., and R. W. Clayton, $P$ and $S$ wave travel time inversions for subducting slab under the island arcs of the northwest Pacific, J. Geophys. Res., 95, 6829-6851, 1990.

A. Hasegawa, Observation Center for Prediction of Earthquakes and Volcanic Eruptions, Faculty of Science, Tohoku University, Sendai 980, Japan.

H. Kanamori and D. Zhao, Seismological Laboratory 25221, California Institute of Technology, Pasadena, CA 91125, USA.

(Received June 28, 1993; revised April 25, 1994; accepted April 28, 1994.) 